\title{
EVOLUTION AND ADAPTATION IN THE PALPUS OF MALE SPIDERS.
}

\author{
Jas. A. NeLson.
}

The following conclusions are the results of study of 85 representatives of 2 I families of American spiders, taken from the collection in Cornell University, through the courtesy of Professor Comstock.

The simplest form - structurally - of the male palpus is that found in the sub-order Tetrapneumones, which, as is well known, is recognized as including those members of the Araneida which are primative in respect to other structural characters. It will therefore be justifiable on two grounds, namely, the structure of the palpus itself, and the general structure of the members of this group - to regard this form of male palpus as the most primitive existing type, thus enabling us to form some conception of its ancient condition. It accordingly serves to indicate the point of departure from which the other more highly modified types have been developed. This simpler type of male palpus is fairly well defined, although varying in many particulars in the different members of the sub-order. Fig. I is a schematized representation of this type. The essential portion of the palpal organ, the bulb (b), is placed at the end or on the ventral surface of the sixth, tarsal, or terminal segment, if we consider the female palpus as representing the original form of the second pair of appendages. The bulb varies from long pyriform to spheroidal in shape; it is articulated at its base to the tarsal segment by a narrow zone of unchitinized integument, and bears at its summit a tapering process, or style $(s)$ Within the bulb is a tubular canal, coiled in a helicoid curve. This canal is wider at its base and narrows gradually toward its peripheral end, which passes into the style and opens at its apex by a narrow aperture. Its function is to contain the sperm and it is therefore termed the semeniferous canal (represented in dotted outline). It is important to note the position of the helicoid curve just mentioned. It is placed in such a manner that its central axis, the helical line (represented in the figures by an arrow), passes through the base of the style at the distal end of the bulb, and the base of the bulb itself at its central end, in this 
primitive type, and moreover it generally coincides with the long axis of the bulb, whenever this is in evidence. This line or axis is a valuable basis for orientation in the manifold changes in form undergone by the bulb in the higher families, and I will, for convenience, term it the principal axis of the bulb. This axis, as the figure shows, generally forms an angle of from 50 to 90 degrees with the long axis of the tarsal joint. Four characters are to be noted as marking this type of palpus: (a) the more or less cylindrical form of the tarsal joint; (b) the position of the bulb, frequently terminal and rarely, if ever, near the base of the tarsus; (c) the narrowness of the zone of articular membrane joining cymbium and bulb, scarcely wider than that between the joints of other appendages; (d) the integument of the bulb itself, which is a continuous chitinized sheet, not broken up into segments or plates. This type of bulb I propose to designate by the term holochitinous.

Turning to the palpal organ of a representative of the higher spider families in the Dipneumones (figs. $2-7$ ) it is seen that the primitive type just described has undergone great alteration, especially in regard to one or more of the four characters described. These are, broadly speaking, the following: (a) change in the form of the tarsal segment or cymbium; $(c)$ this has become compressed in a plane at right angles to that in which the bulb lies, so as to present an elliptical or oval outline in face view, and is moreover hollowed out beneath the base of the bulb to form the alveolus (a); (b) The position of the bulb is uniformly near the base of the cymbium, never, in the higher groups, near its apex; (c) the articular membrane joining bulb and cymbium has increased greatly in extent, and has become an elastic sac (figs. 6 and 7 ) capable of being greatly distended by blood pressure, thus erecting the bulb, thrusting it out some distance from the alveolus and away from the cymbium. It is accordingly termed the haematodocha; (d) The bulb itself has suffered alteration in that it is now generally split transversely into two or more segments, united by membranous integument. It is also frequently greatly shortened in its principal axis.

Each one of the above mentioned alterations of the primitive type seem quite evidently directed toward one end, namely, protection of the bulb, the essential part of the copulatory organ, from mechanical injury. Taking the above four named alterations in order: (a) Change in the shape of the tarsal joint, from 
cylindrical to a flat boat-shaped form, hollowed out on the side toward the palpus, would very evidently be of service in shielding the bulb from mechanical or other injuries.

(b) Change in the position of the bulb, from an exposed position at or near the tip of the cymbium, is correlated with the change in the form of the cymbium mentioned under (a), and enables the bulb to make full use of this alteration.

(c) The distensibility of the articular membrane makes a long or projecting bulb less necessary, since it may be projected at the time of copulation, and only then.

(d) The purpose of splitting the bulb into segments or plates is, in the majority of cases, less evident, but in one large family, the Lycosidae, it enables the bulb to be closely folded together in the alveolus.

The whole evolution of the male palpus, therefore, appears to hinge on the one adaptation, and the different modifications in the form of the palpal organ are accordingly only illustrations of the different means which may be employed to serve this end. Above all stands out the constant mechanical adaptation or fitting together of bulb and cymbium to one another, often carried to an extraordinary degree. When the palpus is at rest, the bulb and cymbium together, in the majority of the Dipneumones, form a compact, more or less ovoid mass. This is brought about, gengenerally speaking, in one of five ways, thus dividing the American spider families of the sub-order Dipneumones into at least five divisions. The lines of separation between these divisions, are, of course, not always sharply marked, since transitional forms occur, but the types themselves are nevertheless quite distinguishable. They are as follows:

I. First of all are those families in which the structure of the male palpus differs little, if any, from that described for the Tetrapneumones. These families are:

Filistatidae.

Dysderidae.

Sicariidae (Scytodes).

The Pholcidae are probably also to be placed here. It is to be noted, that the cymbium of Dysdera crocata shows evidence of the flattening so constantly present in the higher families.

2. Fig. 2. The principal axis is greatly shortened, the bulb is in cross section nearly circular, and sinks into the circular 
alveolus like a ball into a socket. The principal axis is approximately perpendicular to the long axis of the cymbium. Representatives:

Thomisidae (in part).

Agalenidae.

Pisauridae.

Oxyopidae.

Dictynidae.

3. Fig. 3. This is apparently derived from the second type. The principal axis is not only much shortened, but the bulb is elongated in a new axis at right angles to the principal axis and parallel to the long axis of the cymbium, the alveolus being correspondingly extended so as to receive the basal half of the bulb, and therefore oval or elliptical in outline. Representatives:

Thomisidae (in part).

Clubionidae.

Gnaphosidae.

4. Figs. 4, 6, and 7. The alveolus is extended so as to include practically the entire ventral face of the cymbium, reducing the latter to a mere concave shell. In the closed palpus the distal portion of the cymbium lies against the side of the bulb, in other words, the principal axis forms an angle much less than 90 degrees with the long axis of the cymbium. Representatives:

Theridiidae.

Argiopidae.

Mimetidae.

Uloboridae.

5. Fig. 5. The chitinized covering of the bulb, particularly of its distal end, is reduced in extent, so that the bulb is largely composed of thin membrane and is therefore collapsible, in its inactive condition being folded up into a flat package, almost completely contained in the shallow alveolus, which, as in the first division, is moderate in size. The principal axis is slightly oblique to the long axis of the cymbium. Represented only by the

\section{Lycosidae.}

These modifications in the form of the bulb and cymbium, which appear so clearly to be designed for the protection of the former, are aided by special modifications or structures directed 
toward the same end. Two of these are worthy of mention. They are: The accessory branch of the cymbium found in the Linyphiinae and Tetragnathinae, sub-families of the family Argiopidae, (figs. 6 a.b.), and the expanded patella of the Theridiidae (fig. 7 p). Both of these structures serve to overlie and protect the base of the bulb.

To conclude: The more complex palpi found in the Dipneumones have been developed by modification of a palpus similar to that of fig. I. and the principal factor in their evolution has apparently been that of protection from mechanical injury.

\section{EXPLANATION OF PLATE XIII.}

Fig. 1. Diagram of $\sigma^{\pi}$ palpus of the most simplified form.

Fig. 2. तो palpus of Misumena, slightly digrammatic.

Fig. 3. $\sigma^{7}$ palpus of Phurolithus, from camera drawings.

Fig. 4. त palpus of Araneus, schematic.

Fig. 5. त palpus of Lycosa, also schematised.

Fig. 6. 万 palpus of Erigone autumnalis, from a camera sketch.

Fig. 7. $\sigma^{7}$ palpus of Lithyphantes corollatus, also from a camera sketch.

The strongly chitinized portions of the palpus are represented in heavy outline, the membraneous portions, including the haematodocha, in lighter outline. The semeniferous canal is represented by dotted outlines, the principal axis, in each case, by an arrow. The morphological ventral side is turned upward.

$a$, alveolus; $a . b$. , accessory_branch; $b$, bulb; $c$, cymbium; $h$, haematodocha; p. patella. 

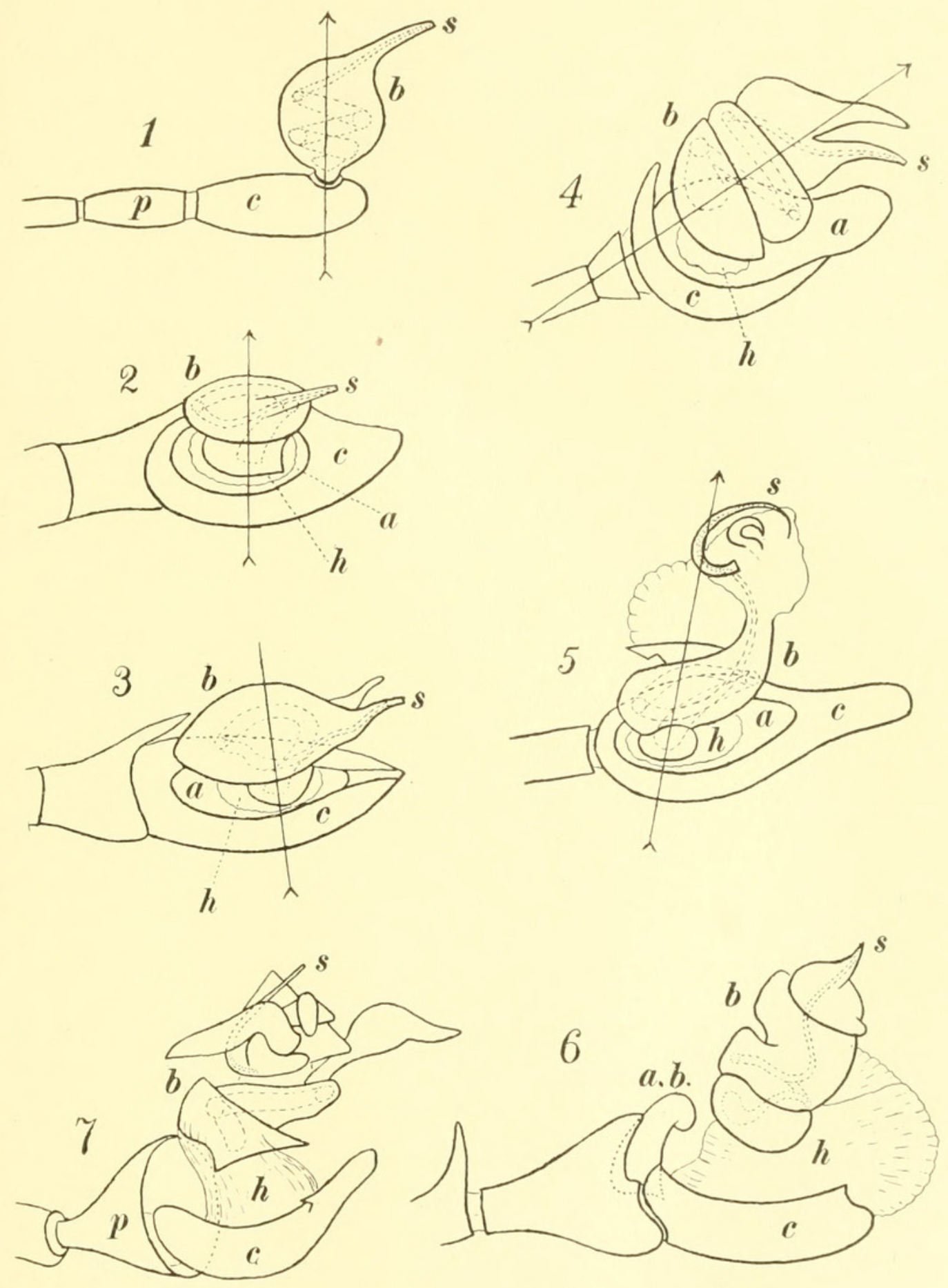



\section{$2 \mathrm{BHL}$ Biodiversity Heritage Library}

Nelson, J A . 1909. "Evolution and Adaptation in the Palpus of Male Spiders." Annals of the Entomological Society of America 2, 60-66.

https://doi.org/10.1093/aesa/2.1.60.

View This Item Online: https://www.biodiversitylibrary.org/item/38095

DOI: https://doi.org/10.1093/aesa/2.1.60

Permalink: https://www.biodiversitylibrary.org/partpdf/193503

\section{Holding Institution}

Smithsonian Libraries

\section{Sponsored by}

Smithsonian

\section{Copyright \& Reuse}

Copyright Status: NOT_IN_COPYRIGHT

This document was created from content at the Biodiversity Heritage Library, the world's largest open access digital library for biodiversity literature and archives. Visit BHL at https://www.biodiversitylibrary.org. 